\title{
Efeitos de Fontes Protéicas na Dieta sobre a Morfologia Intestinal e o Desenvolvimento Pancreático de Leitões Recém-Desmamados ${ }^{1}$
}

\author{
Antônio João Scandolera ${ }^{2}$, Maria Cristina Thomaz ${ }^{3}$, Rodolfo Nascimento Kronka ${ }^{3}$, Alessandro \\ Luís Fraga ${ }^{2}$, Fábio Enrique Lemos Budiño, Rizal Alcides Robles Huaynate ${ }^{2}$, Urbano dos Santos \\ Ruiz $^{2}$, José Cristani²
}

\begin{abstract}
RESUMO - Objetivou-se neste trabalho analisar os efeitos do uso de hidrolisado protéico do conteúdo celular de levedura (HPCCL), da proteína isolada de soja (PIS), do hidrolisado protéico de mucosa intestinal de suínos (HPMIS) e do leite em pó integral em substituição parcial ao farelo de soja sobre a morfologia do intestino delgado e o desenvolvimento pancreático de leitões aos 7 e 14 dias pós-desmame. Foram utilizados 44 leitões desmamados aos 21 dias de idade, com peso de 5,5 $\pm 0,6 \mathrm{~kg}$, alimentados desde o desmame com as seguintes dietas isonutritivas: FS - ração à base de milho e farelo de soja; LPI - ração FS + leite em pó integral; LPI+HPMIS - ração LPI mais HPMIS; LPI+PIS - ração LPI mais PIS; LPI+HPCCL - ração LPI mais HPCCL. Os tratamentos não influenciaram a morfologia intestinal dos leitões, evidenciando que nenhuma das fontes protéicas utilizadas foi capaz de minimizar os efeitos deletérios da mudança da alimentação sobre a vilosidade intestinal. Os animais alimentados com LPI+PIS e LPI+HPMIS apresentaram, aos sete dias pós-desmame, o maior desenvolvimento pancreático. Concluiu-se, portanto, que todas as fontes protéicas estudadas foram igualmente adequadas para a formulação de dietas de desmame.
\end{abstract}

Palavras-chave: epitélio intestinal, leite em pó, leitões, proteína hidrolisada

\section{Effects of Feeding Protein Sources on Morphology and Pancreas Development for Weaned Piglets}

\begin{abstract}
This trial was carried out to evaluate the effects of replacing soybean meal with hydrolyzed protein of the cellular content of yeast (HPCCY), isolated protein of soy (IPS), hydrolyzed protein of intestinal mucosa membrane of swine (HPIMS) and dried whole milk on intestinal mucosa membrane morphology and pancreas development of weaned pigs at 7 and 14 days post weaning. Fourty-four piglets (averaging $5.5 \pm 0.6 \mathrm{~kg}$ ) were fed the following isonutritive diets: $\mathrm{SM}$-yellow corn-soybean meal based diet; DWM - SM plus dried whole milk; DWM+HPIMS - DWM plus HPIMS; DWM+IPS - DWM plus IPS; DWM+HPCCY - DWM plus HPCCY. The treatments did not influence the pig intestinal structure, showing that none of the protein sources minimized the harmful effects of feeding change on the intestinal epithelium. DWM+HPIMS and DWM+IPS provided the greatest pancreatic weight at 7 days post weaning. It was concluded that all studied protein sources were adequate to formulate diets for weaned piglets.
\end{abstract}

Key Words: hydrolyzed protein, intestinal epithelium, milk dried, piglets

\section{Introdução}

O desmame é uma fase crítica do desenvolvimento de leitões. Por ocasião deste processo, a mucosa intestinal altera-se, diminuindo as capacidades digestiva e absortiva do intestino delgado (Cera et al., 1988), como conseqüência da maior descamação do epitélio intestinal, reduzindo a altura dos vilos e aumentando a profundidade das criptas em resposta a esta agressão (Argenzio, 1993).

Entre os fatores que afetam a morfologia intestinal, destacam-se a invasão por microrganismos, a presença de alimento no lume intestinal, a quantidade de alimento ingerido (Pluske et al., 1997) e o contato com compostos alergênicos (Li et al.,1991). O farelo de soja, principal fonte protéica nas dietas de suínos, contém glicina e betaconglicinina, proteínas capazes de provocar respostas de hipersensibilidade e alterar o epitélio intestinal dos leitões (Li et al., 1990).

Por sua vez, o desenvolvimento do pâncreas e a produção de enzimas digestivas são estimulados após o desmame (Kelly et al., 1991), principalmente pela presença do farelo de soja na dieta (Effird et al., 1982). Segundo Pierzynowski et al. (1993), as mudanças na função pancreática de leitões parecem ser conseqüência da adaptação à dieta sólida contendo até três vezes mais proteínas e carboidratos que o leite materno.

\footnotetext{
1 Parte da tese de doutorado do primeiro autor. CAPES.

2 Aluno do Programa de Pós-Graduação em Zootecnia da FCAV/UNESP - Campus de Jaboticabal.

3 Professor da FCAVIUNESP - Campus de Jaboticabal (thomaz@fcav.unesp.br).
} 
A inclusão de fontes protéicas de origem animal (entre 5 e 10\%), como os produtos lácteos, os subprodutos da indústria frigorífica e de ingredientes vegetais (Ludke et al., 1998) e os produtos obtidos a partir de leveduras utilizadas em destilarias, em dietas para leitões ao desmame é recomendada por sua alta digestibilidade.

O objetivo neste estudo foi avaliar o efeito da substituição parcial do farelo de soja (FS) pelo hidrolisado protéico do conteúdo celular de levedura (HPCCL), pela proteína isolada de soja (PIS) ou pelo hidrolisado protéico de mucosa intestinal de suínos (HPMIS), em combinação com o leite em pó integral (LPI), na alimentação de leitões recémdesmamados sobre a morfologia da mucosa do intestino delgado e o desenvolvimento pancreático aos 7 e 14 dias pós-desmame.

\section{Material e Métodos}

Foram utilizados 44 leitões (fêmeas e machos castrados) desmamados aos 21 dias de idade, com peso inicial de 5,5 $\pm 0,6 \mathrm{~kg}$, alojados em baias individuais de $2,55 \mathrm{~m}^{2}$, com piso de concreto e separadas por grades de ferro, equipadas com bebedouro vaso comunicante e comedouro semi-automático.

Utilizaram-se rações isonutritivas (Tabela 1) e isentas de qualquer produto com ação antidiarréica, devidamente suplementadas com minerais e vitaminas, de forma a atender às exigências mínimas descritas pelo NRC (1998). Rações e água foram fornecidas à vontade durante toda a fase experimental (de 21 a 35 dias de idade). Os tratamentos consistiram das seguintes dietas experimentais:

FS - dieta controle, à base de milho e farelo de soja (único ingrediente protéico);

LPI - dieta FS com 15,0\% de leite em pó integral;

LPI+HPMIS - dieta FS com 15,0\% de leite em pó integral e 3,5\% de hidrolisado protéico de mucosa intestinal de suínos;

LPI+PIS - dieta FS com 15,0\% de leite em pó integral e $5,0 \%$ de proteína isolada de soja;

LPI+HPCCL - dieta FS com 15,0\% de leite em pó integral e 5,0\% de hidrolisado protéico de conteúdo celular de levedura.

Os níveis de inclusão e os valores nutricionais dos hidrolisados protéicos de membrana intestinal de suínos, de conteúdo celular de levedura e da proteína isolada de soja foram estimados considerando-se as recomendações dos fabricantes. A composição dos demais ingredientes das rações foi obtida na base de dados do software SuperCrac 3.0.

Os animais foram abatidos no início do experimento aos 28 e 35 dias de idade ( 0,7 e 14 dias pósdesmame, respectivamente), após jejum alimentar por 12 horas, sem restrição à água.

Logo após o abate, foram coletadas amostras das porções médias do duodeno e do jejuno para realização da técnica de microscopia de luz e eletrônica de varredura. Foram pesados o pâncreas (peso absoluto) e a carcaça (sem vísceras, pelos e unhas) dos animais, para determinação do peso relativo do pâncreas (peso absoluto do pâncreas/peso da carcaça).

Para o estudo da microscopia de luz, as amostras do duodeno e do jejuno foram mantidas em solução fixadora de Bouin, durante 24 horas, desidratadas em série crescente de alcoóis, submetidas à bateria de benzol, incluídas em parafina e microtomizadas, para a montagem de duas lâminas de cada amostra. Em cada lâmina foram colocados seis cortes semi-seriados de $5 \mathrm{~mm}$ de espessura. A seguir, uma preparação de cada amostra foi corada pela técnica de hematoxilina de Harris-eosina de Erlich (HE) e outra pela de Tricrômico de Masson, segundo Behmer et al. (1976).

Os cortes foram analisados em microscópio de luz, modelo Olympus BX41, acoplado a um sistema para captura de imagens Olympus DP11-N. Foram registradas a altura e largura do vilo, a profundidade da cripta (aumento $100 \mathrm{x}$ ) e a espessura das camadas mucosa, submucosa e muscular + serosa (aumento $40 \mathrm{x}$ ), utilizando-se o software Image-Pro Plus ${ }^{\circledR}$.

A partir destes dados, foram calculadas a relação vilo/cripta (altura do vilo / profundidade de cripta) e a espessura total da parede intestinal (espessuras da mucosa + submucosa + muscular + serosa).

Para o estudo em microscopia eletrônica de varredura, as amostras do duodeno e dojejuno, imediatamente após a coleta, foram fixadas em glutaraldeído 3\%, lavadas em solução tampão cacodilato de sódio $0,1 \mathrm{M}$ e pH 7,2 e pós-fixadas em tetróxido de ósmio a 1\%.

Depois da desidratação em série crescente de álcoois, foi feita a embebição dos tecidos em solução de acetato de isoamila por 3 horas. O material foi seco, em dióxido de carbono (CO2) líquido em secadora de ponto crítico modelo EMS 850, e metalizado com ouro paládio, utilizando-se o aparelho DENTON VACUM modelo Desk II. 
Tabela 1- Composição centesimal e níveis nutricionais das rações experimentais oferecidas aos leitões durante a fase experimental (21 a 35 dias de idade)

Table 1 - Ingredient composition and nutritional levels of experimental diets fed to pigs during experimental phase (21 to 35 days old)

\begin{tabular}{|c|c|c|c|c|c|}
\hline \multirow[t]{2}{*}{$\begin{array}{l}\text { Ingrediente }(\%) \\
\text { Ingredient }\end{array}$} & \multicolumn{5}{|c|}{$\begin{array}{c}\text { Dieta } \\
\text { Diet }\end{array}$} \\
\hline & $\begin{array}{c}\mathrm{LPI}+\mathrm{HPCCL} \\
D W M+H P C C Y\end{array}$ & $\begin{array}{c}\mathrm{LPI}+\mathrm{PIS} \\
D W M+I P S\end{array}$ & $\begin{array}{c}\text { LPI+HPMIS } \\
D W M+H P I M S\end{array}$ & $\begin{array}{c}\text { LPI } \\
D W M\end{array}$ & $\begin{array}{l}\mathrm{FS}^{\mathrm{f}} \\
S M\end{array}$ \\
\hline Milho (Yellow corn) & 45,16 & 48,00 & 42,38 & 42,73 & 54,49 \\
\hline Farelo de soja (Soybean meal) & 24,93 & 19,81 & 27,10 & 30,87 & 37,28 \\
\hline Açúcar (Sugar) & 1,00 & 1,00 & 1,00 & 1,00 & 1,00 \\
\hline Calcário calcítico (Limestone) & 1,10 & - & 1,15 & 0,94 & 1,13 \\
\hline Fosfato bicálcico (Dicalcium phosphate) & 1,02 & 3,27 & 1,34 & 1,65 & 1,82 \\
\hline Óleo de soja (Soybean oil) & 3,00 & 3,00 & 3,00 & 3,00 & 3,00 \\
\hline DL-metionina $(99 \%)$ & 0,02 & 0,06 & 0,040 & 0,05 & 0,06 \\
\hline $\begin{array}{l}\text { DL-methionine } \\
\text { L-lisina } \mathrm{HCl}(78 \%)\end{array}$ & & & & & \\
\hline $\begin{array}{l}\text { L-lysine } \\
\text { L-treonina }(98 \%)\end{array}$ & 0,12 & 0,12 & 0,09 & 0,09 & 0,19 \\
\hline $\begin{array}{l}\text { L-threonine } \\
\text { L-triptofano }(98 \%)\end{array}$ & - & - & - & - & 0,01 \\
\hline L-tryptophan & 0,015 & 0,010 & 0,015 & 0,010 & - \\
\hline Supl. vitam. e min. ${ }^{a}$ & 0,10 & 0,10 & 0,10 & 0,10 & 0,10 \\
\hline Vitamin mineral mix & & & & & \\
\hline Sal comum (Salt) & 0,39 & 0,55 & - & 0,59 & 0,64 \\
\hline $\mathrm{HPCCL}^{\mathrm{b}}(\mathrm{HPCCY})$ & 5,00 & - & - & - & - \\
\hline $\operatorname{PIS}^{\mathrm{c}}(I P S)$ & - & 5,00 & - & - & - \\
\hline HPMIS $^{\mathrm{d}}$ (HPIMS) & - & - & 3,50 & - & - \\
\hline $\mathrm{LPI}^{\mathrm{e}}(D W M)$ & 15,00 & 15,00 & 15,00 & 15,00 & - \\
\hline BHT & 0,01 & 0,01 & 0,01 & 0,01 & 0,01 \\
\hline Inerte (Inert) & 3,14 & 4,07 & 5,28 & 3,96 & 0,27 \\
\hline
\end{tabular}

Nível nutricional calculado

Calculated nutritional level

$\mathrm{ED}, \mathrm{kcal} / \mathrm{kg}$ (Digestible energy)
3.400
0,90
1,35
0,86
0,20

$\begin{array}{lr}\text { Proteína bruta, \% (Crude protein) } & 22,00 \\ \text { Lactose, \% (Lactosis) } & 4,80 \mathrm{~b}\end{array}$

Cálcio, \% (Calcium)

$\begin{array}{lr}\text { Fósforo disponível, \% (Avaiable phosphorus) } & 0,40 \\ \text { Metionina, \% (Methionine) } & 0,40\end{array}$

Metionina + Cistina, \% (Methionine + cystine) $\quad 0,76$

Lisina, \% (Lysine)

Treonina, \% (Threonine)

Triptofano, \% (Tryptophan) $\quad 0,30$

Sódio, \% (Sodium)

a Suplemento vitamínico e mineral Frimix® Suinomix (Fri-Ribe) - Níveis de garantia por kg do produto [Vitamin mineral mix Frimix ${ }^{\circledR}$ Suinomix (FriRibe] - Guarantee levels by kg of product): Vit A 4.000.000 UI, Vit D3 220.000 Ul, Vit E 22.000 mg, Vit K 500 mg, Vit B2 3.750 mg, Vit B12 20.000 mcg, Pantotenato de cálcio (Pantothenic acid) $12.000 \mathrm{mg}$, Niacina (Niacin) $20.000 \mathrm{mg}$, Colina (Choline) $60.000 \mathrm{mg}$, lodo (lodine) $140 \mathrm{mg}$, Selênio (Selenium) $30 \mathrm{mg}$, Manganês (Manganese) $10.000 \mathrm{mg}$, Ferro (Iron) $99.000 \mathrm{mg}$, Antioxidante (Antioxidant) $125 \mathrm{mg}$.

b Hidrolisado protéico do conteúdo celular de levedura (Hydrolyzed protein of cellular content of yeast) - NuproTM - Alltech do Brasil. Na dieta FS não foi fornecida lactose (in SM diet lactosis was not supplied).

c Proteína isolada de soja (Isolated protein of soybean) - Samprosoy FG 90 - Bunge Alimentos S.A.

d Hidrolisado protéico de mucosa intestinal de suíno (Hydrolyzed protein of intestinal mucosa membrane of swine) - DPS 50 RD - Porsol@ - Nutraflo Company.

e Leite em pó integral (Dried whole milk).

f Dieta à base de milho e farelo de soja (Corn-soybean meal based diet). 
Realizaram-se três eletronmicrografias por amostra, para contagem e determinação da largura dos vilos e posterior cálculo da densidade de vilos (vilos $/ \mathrm{cm}^{2}$ ), em microscópio eletrônico de varredura JEOL JSM 5410 , operado a $15 \mathrm{kv}$.

Foi utilizado o delineamento em blocos casualizados (para controlar diferenças iniciais de peso), em esquema fatorial $5 \times 2+1$ (cinco dietas e duas épocas de abate), com quatro repetições por tratamento, sendo que no dia do desmame foram abatidos quatro leitões. Os dados foram analisados pelo procedimento "General Linear Model" (GLM) do "software" estatístico "Statistical Analysis System" (SAS, 1985) e as médias foram comparadas pelo teste Tukey (5\%).

Adotou-se o seguinte modelo matemático:

$$
Y i j k=m+T i+E j+(T E) i j+B k+e i j k,
$$

em que: $Y i j k=$ valor observado para a dieta $\mathrm{i}$, na época de abate $\mathrm{j}$, no bloco $\mathrm{k} ; \mathrm{m}=$ média geral; $\mathrm{Ti}=$ efeito $\mathrm{da}$ dieta $\mathrm{i} ; \mathrm{Ej}=$ efeito da época de abate $\mathrm{j} ;(\mathrm{TE}) \mathrm{ij}=$ efeito da interação entre a dieta $\mathrm{i}$ e a época de abate $\mathrm{j} ; \mathrm{Bk}=$ efeito do bloco k; eijk = erro experimental.

\section{Resultados e Discussão}

Os dados referentes às análises morfométricas da mucosa intestinal encontram-se nas Tabelas 2, 3 e 4 .

Aos 7 dias pós-desmame, as reduções $(\mathrm{P}<0,05)$ na altura dos vilos do duodeno e jejuno foram de $59 \mathrm{e}$ $55 \%$, respectivamente, e mantiveram-se até o $14^{\circ}$ dia pós-desmame. Menores reduções de altura dos vilos ( $20 \%$ no duodeno e $25 \%$ no jejuno) foram descritas por Hannas (2003), porém utilizando dietas mais complexas que as deste trabalho.

Houve redução $(\mathrm{P}<0,05)$ de $27 \%$ aos 7 dias pósdesmame em relação ao dia zero (desmame), com recuperação aos 14 dias pós-desmame, apresentando-se apenas $8 \%$ menor em relação ao desmame. A

Tabela 2 - Efeito da idade e da dieta sobre a altura (AV), largura do vilo (LV), profundidade de cripta (PC) e a relação altura do vilo/profundidade de cripta (AV/PC) do duodeno e jejuno de leitões

Table 2 - Effect of age and diets on villous height (VH), width (VW), crypt depth (CD) and villous height:crypt depth ratio (VH/CD) of duoden and jejuni of pigs

\begin{tabular}{|c|c|c|c|c|c|c|c|c|}
\hline \multirow[t]{3}{*}{$\begin{array}{l}\text { Causas de variação } \\
\text { Source of variation }\end{array}$} & \multicolumn{4}{|c|}{$\begin{array}{l}\text { Duodeno } \\
\text { Duoden }\end{array}$} & \multicolumn{4}{|c|}{$\begin{array}{l}\text { Jejuno } \\
\text { Jejuni }\end{array}$} \\
\hline & AV & LV & $\mathrm{PC}$ & $\mathrm{AV} / \mathrm{PC}$ & AV & LV & $\mathrm{PC}$ & $\mathrm{AV} / \mathrm{PC}$ \\
\hline & $V H$ & $V W$ & $C D$ & $V H / C D$ & $V H$ & $V W$ & $C D$ & $\mathrm{VH} / \mathrm{CD}$ \\
\hline & \multicolumn{8}{|c|}{$\begin{array}{c}\text { Nível de significância pelo teste F } \\
\text { Significance level by F test }\end{array}$} \\
\hline Idade (Age) & 0,01 & 0,09 & 0,01 & 0,01 & 0,01 & 0,01 & 0,35 & 0,01 \\
\hline Dietas (Diets) & 1,00 & 0,02 & 0,75 & 0,90 & 0,47 & 0,65 & 0,94 & 0,43 \\
\hline Interação (Interaction) & 1,00 & 0,02 & 0,61 & 0,98 & 0,92 & 0,60 & 0,67 & 0,91 \\
\hline $\mathrm{CV}(\%) *$ & 37,3 & 41,4 & 14,2 & 22,8 & 18,9 & 10,88 & 18,19 & 17,99 \\
\hline Dias & \multirow{2}{*}{\multicolumn{8}{|c|}{ Média $(\mathrm{mm})^{2}$}} \\
\hline Days & & & & & & & & \\
\hline 0 & $584^{\mathrm{a}}$ & 143 & $228^{\mathrm{a}}$ & $2,56^{\mathrm{a}}$ & $480^{\mathrm{a}}$ & $111^{\mathrm{b}}$ & 191 & $2,51^{\mathrm{a}}$ \\
\hline 7 & $239^{\mathrm{b}}$ & 185 & $166^{\mathrm{c}}$ & $1,46^{\mathrm{b}}$ & $213^{\mathrm{b}}$ & $115^{\mathrm{b}}$ & 175 & $1,21^{\mathrm{b}}$ \\
\hline 14 & $228^{b}$ & 147 & $188^{\mathrm{b}}$ & $1,22^{\mathrm{b}}$ & $211^{\mathrm{b}}$ & $127^{\mathrm{a}}$ & 184 & $1,14^{\mathrm{b}}$ \\
\hline Dieta $^{1}$ & \multirow{2}{*}{\multicolumn{8}{|c|}{$\begin{array}{l}\text { Média }(\mathrm{mm})^{2} \\
\text { Mean }\end{array}$}} \\
\hline Diet & & & & & & & & \\
\hline $\mathrm{FS}(S M)$ & 347 & 149 & 197 & 1,67 & 288 & 123 & 188 & 1,55 \\
\hline $\operatorname{LPI}(D W M)$ & 358 & 144 & 201 & 1,71 & 289 & 118 & 186 & 1,58 \\
\hline LPI+HPMIS (DWM+HPIMS) & 338 & 145 & 191 & 1,69 & 299 & 118 & 184 & 1,61 \\
\hline LPI+PIS $(D W M+I P S)$ & 354 & 135 & 186 & 1,82 & 326 & 115 & 183 & 1,78 \\
\hline LPI+HPCCL $(D W M+H P C C Y)$ & 354 & 220 & 194 & 1,75 & 306 & 116 & 177 & 1,67 \\
\hline
\end{tabular}

R. Bras. Zootec., v.34, n.6, p.2355-2368, 2005 (supl.) 
em ambos os segmentos, dos animais alimentados com dieta contendo leite em pó integral + hidrolisado protéico de conteúdo celular de levedura, que aparentaram maior desgaste, ainda que de forma menos expressiva.
Evidenciou-se que os efeitos das rações sobre a morfologia da mucosa intestinal foram similares e que nenhuma das fontes protéicas utilizadas foi capaz de minimizar os efeitos deletérios da mudança na alimen-

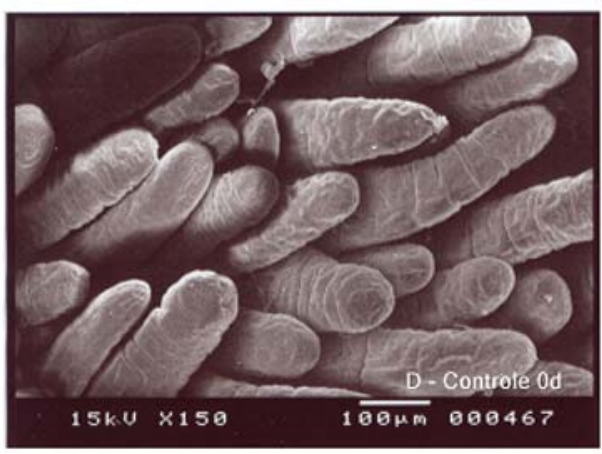

D - 0 dia pós-desmame - Controle $D$-weaning day-Control

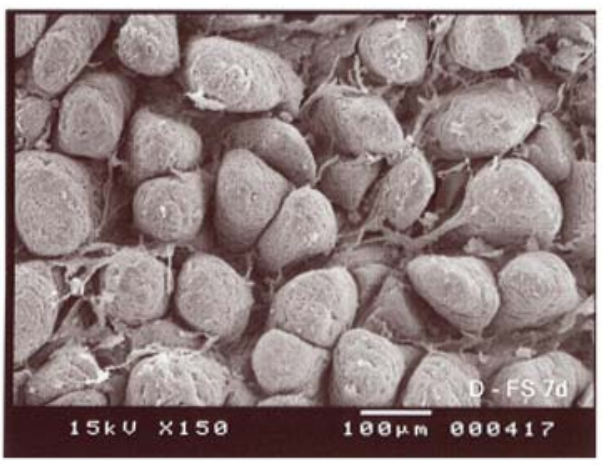

D - 7 dias pós-desmame - FS D- 7-day-weaned - SM

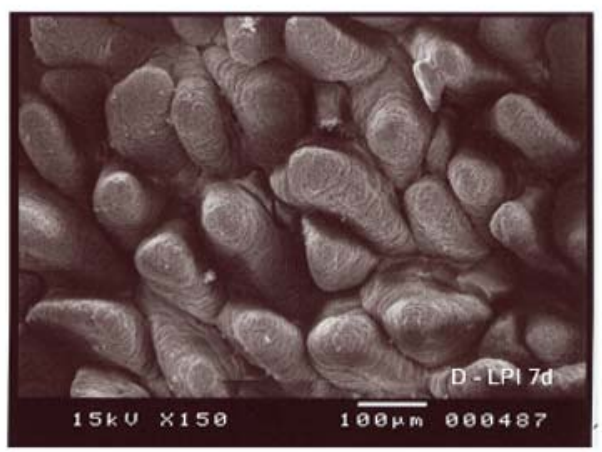

D - 7 dias pós-desmame - LPI $D-7$-day-weaned- DWM

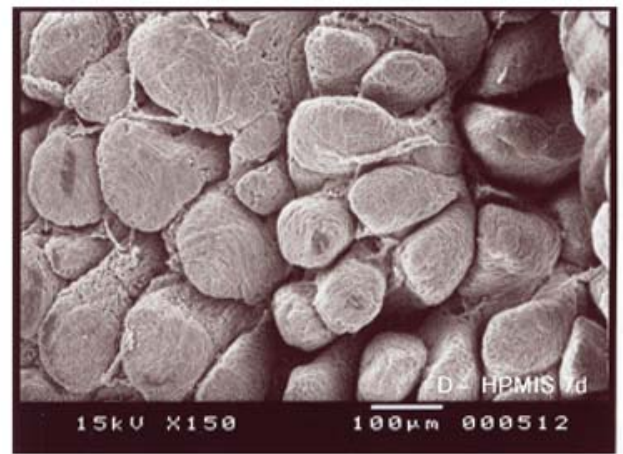

D - 7 dias pós-desmame - HPMIS D-7-day-weaned - HPIMS

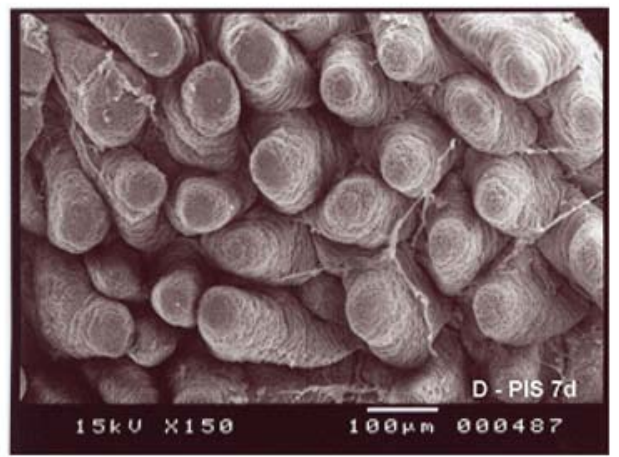

D - 7 dias pós-desmame - PIS $0-7-d a y-$ weaned- IPS

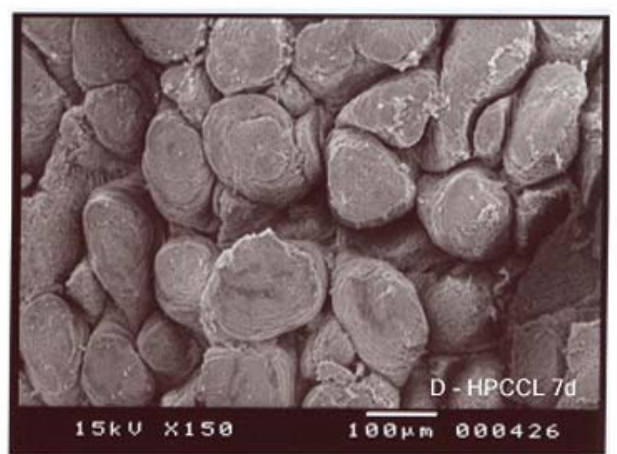

D - 7 dias pós-desmame - HPCCL $D-7-d a y-w e a n e d-H F C C Y$

Figura 1 - Eletronmicrografias de varredura do duodeno (D) de leitões ao desmame (controle) e aos 7 dias após o desmame em função das diferentes fontes protéicas (FS - farelo de soja, LPI - leite em pó integral, HPMIS hidrolisado protéico de mucosa intestinal de suíno, PIS - proteína isolada de soja e HPCCL - hidrolisado protéico de conteúdo celular de levedura). $A=150 X$.

Figure 1 - Scan eletronmicrografy of duodenun (D) from weaning pigs (control) and 7-day-weaned pigs according to different protein sources (SM - soybean meal, WDM - whole dried milk. HPIMS - hydrolized protein of intestinal mucosa membrane of swine, IPS - isolated protein of soybean and HPCCY - hydrolized protein of cellular content of yeast). $I=150 X$.

R. Bras. Zootec., v.34, n.6, p.2355-2368, 2005 (supl.) 
Tabela 4 - Efeitos da idade e da dieta sobre a densidade média dos vilos (vilos $/ \mathrm{cm}^{2}$ ) do duodeno e do jejuno de leitões

Table 4 - Effects of age and diets on mean villous density (vilo/ $\left.\mathrm{cm}^{2}\right)$ of duoden and jejuni of pigs

\begin{tabular}{lcc}
\hline $\begin{array}{l}\text { Causa de variação } \\
\text { Source of variation }\end{array}$ & $\begin{array}{c}\text { Duodeno } \\
\text { Duoden }\end{array}$ & $\begin{array}{c}\text { Jejuno } \\
\text { Jejuni }\end{array}$ \\
\hline Nível de significância pelo teste F \\
Significance levels by
\end{tabular}

${ }^{1} \mathrm{FS}$ (farelo de soja), LPI (leite em pó integral); LPI+HPMIS (leite em pó integral + hidrolisado protéico de mucosa intestinal de suíno); LPI+PIS (leite em pó integral + proteína isolada de soja); $\mathrm{LPI}+\mathrm{HPCCL}$ (leite em pó integral + hidrolisado protéico do conteúdo celular de levedura).

2 Médias com letras iguais na mesma coluna não diferem $(P>0,05)$ entre si pelo teste Tukey.

1 SM (soybean meal), DWM (dried whole milk), DWM+HPIMS (dried whole milk + hydrolized protein of intestinal mucosa membrane of swine), $D W M+I P S$ (dried whole milk + isolated protein of soybean), DWM+HPCCY (hydrolized protein of cellular content of yeast).

${ }^{2}$ Means followed by the same letters in a column do not differ $(P>0.05)$ by Tukey test.

tação sobre os vilos, conforme verificado por McCraken et al. (1999) e Carlson \& Veum (2000), ao compararem proteínas lácteas, plasma ou peptídeos vegetais como subprodutos da soja.

Ressalta-se, contudo, que os leitões deste trabalho tiveram contato com a dieta das matrizes antes do desmame, o que pode ter favorecido a adaptação dos animais às proteínas do farelo de soja e mascarado os efeitos das demais fontes protéicas estudadas.

Leitões alimentados com a dieta contendo leite em pó integral + proteína isolada de soja apresentaram as menores alterações na altura e largura dos vilos e na relação altura do vilo/profundidade de cripta provocadas pela idade, ainda que sem diferença estatística. Estes dados reforçam as observações de Silz
(2000), que relatou integridade da mucosa intestinal de leitões desmamados alimentados com diferentes níveis destes mesmos produtos.

Os resultados obtidos para espessura das diferentes camadas da parede intestinal do duodeno e do jejuno dos animais encontram-se na Tabela 5. As medidas efetuadas nas paredes do duodeno e do jejuno (mucosa, submucosa e muscular + serosa) e a espessura total da parede intestinal foram influenciadas $(\mathrm{P}<0,01)$ pela idade. Aumentos na espessura total da parede intestinal conforme a idade também foram registrados por Carlson \& Veum (2000).

Não houve efeito $(\mathrm{P}>0,05)$ das dietas nem da interação idade dos animais $\mathrm{x}$ dietas sobre as espessuras das camadas da parede intestinal tanto no duodeno quanto no jejuno.

Jiang et al. (2000) também não verificaram alterações significativas da espessura da camada muscular da mucosa e da espessura total da parede intestinal de leitões alimentados com dietas contendo $4 \%$ de plasma suíno em comparação àqueles alimentados com dietas contendo $15 \%$ de soja extrusada.

Para o duodeno, observou-se redução $(\mathrm{P}<0,05)$ da espessura da mucosa entre os dias 0,7 e 14 pósdesmame, o que provavelmente ocorreu em razão da própria diminuição na altura dos vilos, uma vez que esta medida foi tomada do topo do vilo até a muscular da mucosa e a altura do vilo também reduziu conforme a idade.

Ainda no duodeno, houve diferença $(\mathrm{P}<0,05)$ na submucosa entre os dias 0 e 14 pós-desmame. Para muscular + serosa e espessura total, observou-se aumento $(\mathrm{P}<0,05)$ aos 14 dias em relação aos dias 0 e 7 após o desmame.

No jejuno, a menor $(\mathrm{P}<0,05)$ espessura de mucosa foi observada aos 7 dias pós-desmame e as maiores $(\mathrm{P}<0,05)$ espessuras de submucosa, muscular + serosa e total foram encontradas aos 14 dias.

Com base nos estudos de Miller et al. (1984) e Hampson (1986a,b), que associaram o aumento na mucosa ao incremento na multiplicação das criptas, pode-se supor que o aumento verificado na mucosa do jejuno dos 7 aos 14 dias pode ter decorrido do alargamento da lâmina própria, pois é neste estrato da parede intestinal que se concentram as células ligadas ao sistema imunológico e ocorre a multiplicação das células da cripta (Cerf-Bensussan \& Guy-Grand, 1991).

A análise dos dados de espessura da parede intestinal indicou que apenas no duodeno, aos 14 dias 


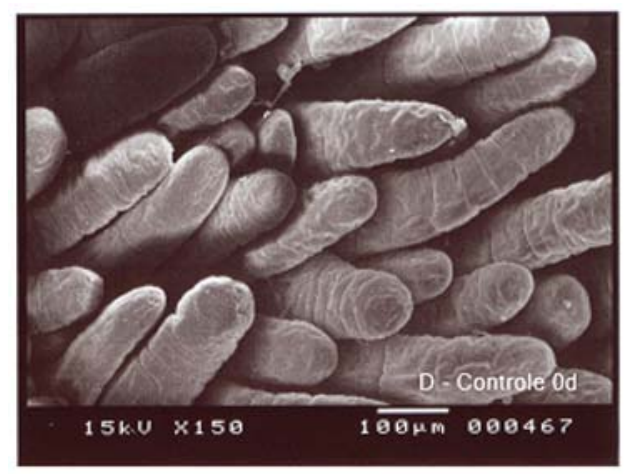

D - 0 dia pós-desmame - Controle $D$-weaning day - Control

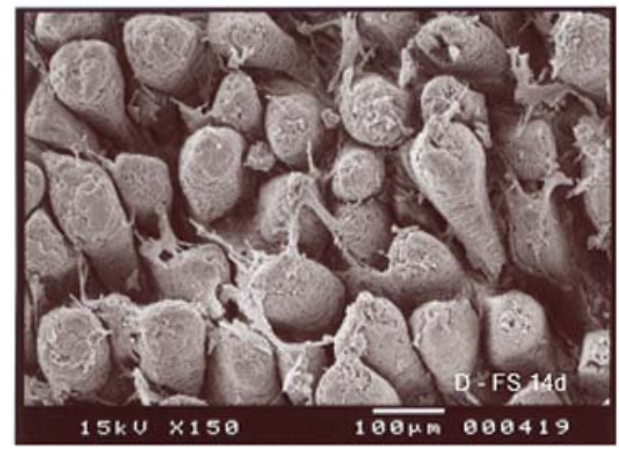
D- 14 dias pós-desmame - FS
$D-14$ day-weaned - SM

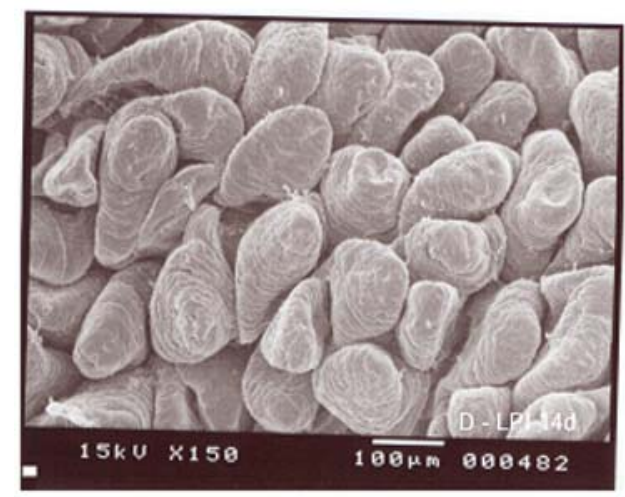

D - 14 dias pós-desmame - LPI $D-14$ day-we aned - OWM

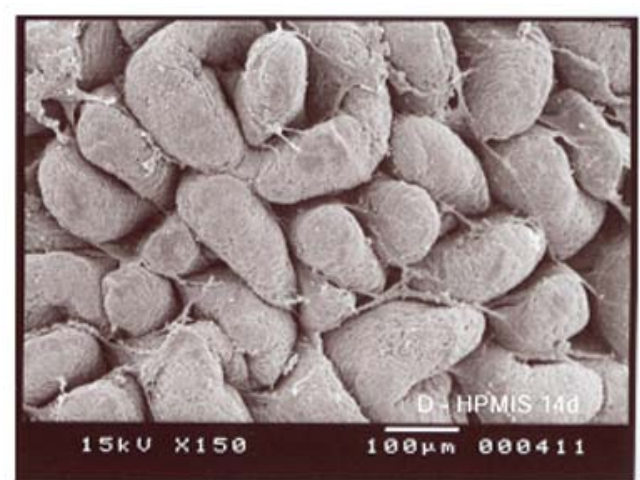

D- 14 dias pós-desmame-HPMIS $D$ - 14-day-weaned - HPIMS

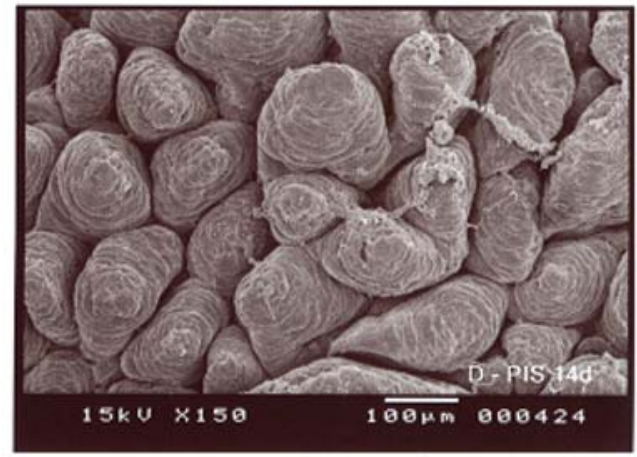

D - 14 dias pós-desmame-PIS $0-14$ day-weaned - IPS

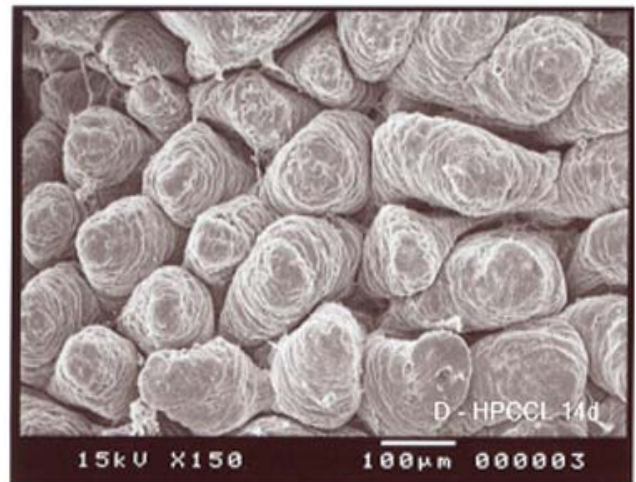

D - 14 dias pós-desmame - HPCCL $D-14$ day-weaned - HPCCY

Figura 2 - Eletronmicrografias de varredura do duodeno (D) de leitões ao desmame (controle) e aos 14 dias pósdesmame, em função das diferentes fontes protéicas (FS - farelo de soja, LPI - leite em pó integral, HPMIS - hidrolisado protéico de mucosa intestinal de suíno, PIS - proteína isolada de soja e HPCCL - hidrolisado protéico de conteúdo celular de levedura). $A=150 \mathrm{X}$.

Figure 2 - Scan eletronmicrografies of duodenun (D) from weaning pigs (control) and 14-day-weaned pigs according to different protein sources (SM - soybean meal, WDM - whole dried milk, HPIMS - hydrolized protein of intestinal mucosa membrane of swine, IPS - isolated protein of soybean and HPCCY - hydrolized protein of cellular content of yeast). $I=150 X$.

R. Bras. Zootec., v.34, n.6, p.2355-2368, 2005 (supl.) 


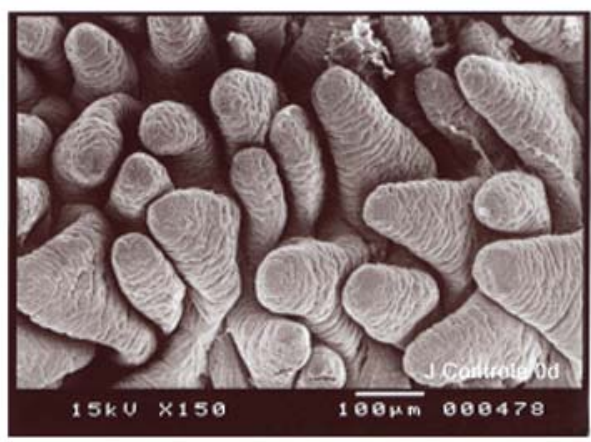

$\mathrm{J}$ - 0 dia pós-desmame - Controle $\checkmark-$ weaning day - Control

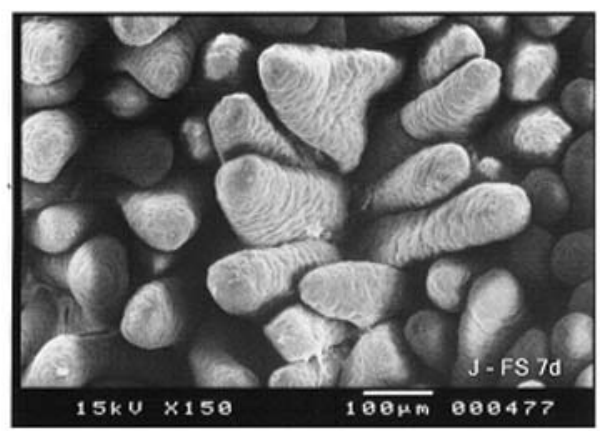

$\mathrm{J}-7$ dias pós-desmame - FS

j-7-day-weaned-SM

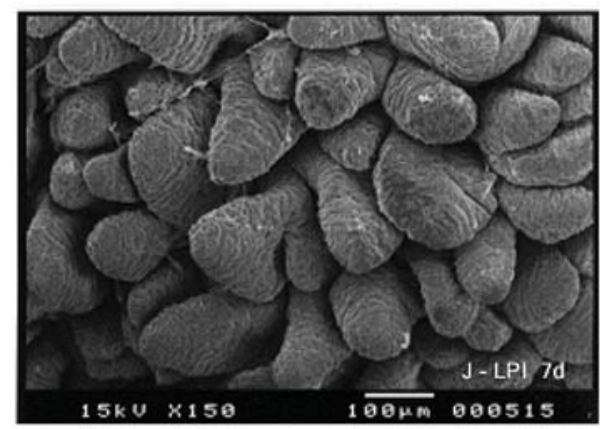

$\mathrm{J}-7$ dias pós-desmame - LPI J-7-day-we aned-DWM

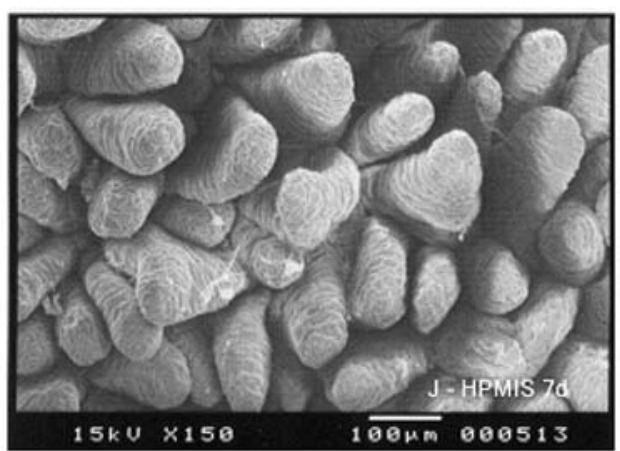

L - 7 dias pós-desmame - HPMIS s-7-day-weaned - HPIMS

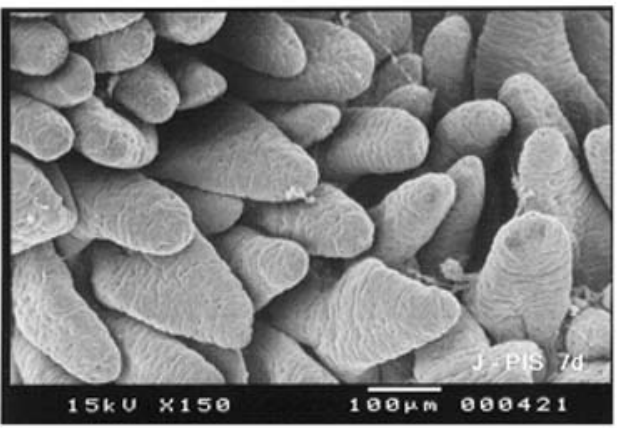

$\mathrm{J}-7$ dias pós-desmame-PIS J-7-day-weaned-IPS

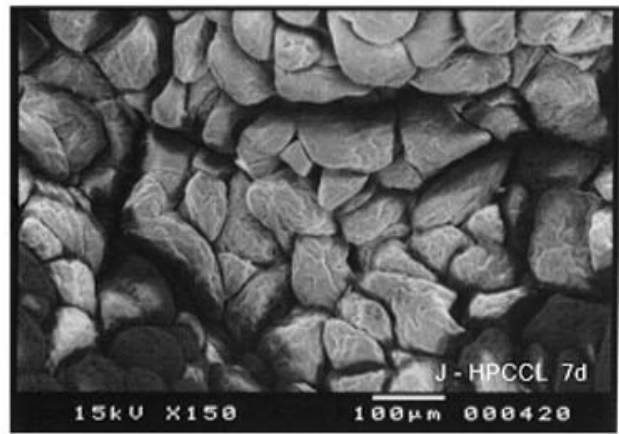

J- 7 dias pós-desmame-HPCCL J-7-day-weaned-HPCCY

Figura 3 - Eletronmicrografias de varredura do jejuno (J) de leitões ao desmame (controle) e aos 7 dias pós-desmame, em função das diferentes fontes protéicas (FS - farelo de soja, LPI - leite em pó integral, HPMIS - hidrolisado protéico de mucosa intestinal de suíno, PIS - proteína isolada de soja e HPCCL - hidrolisado protéico de conteúdo celular de levedura). $A=150 X$

Figure 3 - Scan eletronmicrografies of jejuni $(\mathrm{J})$ from weaning pigs (control) and 7-day-weaned pigs according to different protein sources (SM - soybean meal, WDM - whole dried milk, HPIMS - hydrolized protein of intestinal mucosa membrane of swine, IPS - isolated protein of soybean and HPCCY - hydrolized protein of cellular content of yeast). $I=150 X$.

R. Bras. Zootec., v.34, n.6, p.2355-2368, 2005 (supl.) 


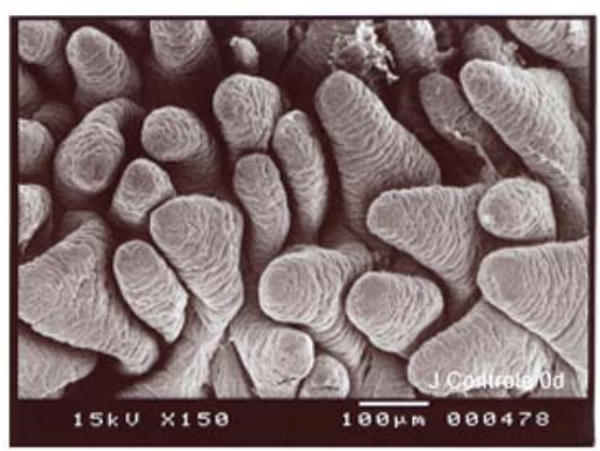

J-0 dia pós-desmame-Controle

$J$-weaning day-Control

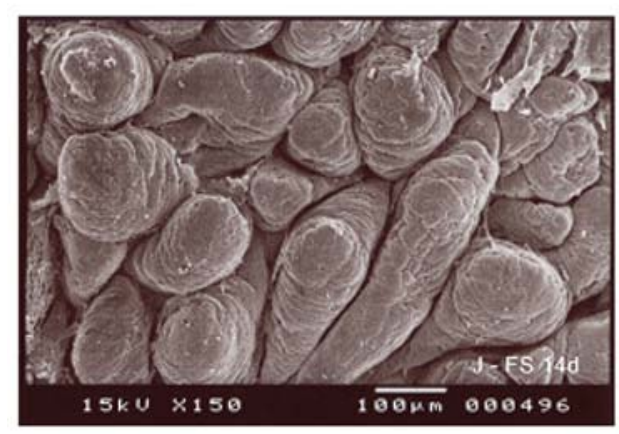

J-14 diaspós-desmame-FS

$J-14-d$ ay-weaned - SA

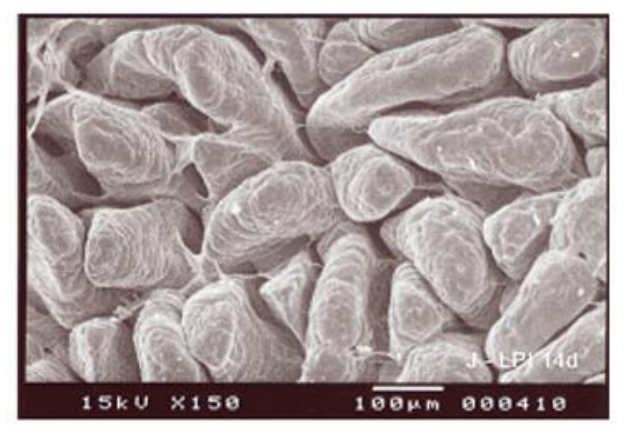

J-14 dias pós-desmame-LPI $s-14-d$ ay-weaned - DWh

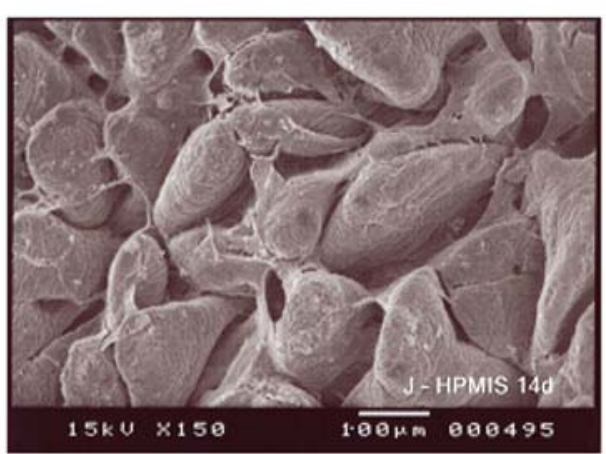

$\mathrm{J}-14$ dias pós-desmame-HPMIS $j-14-d$ ay-weaned - HPIMS

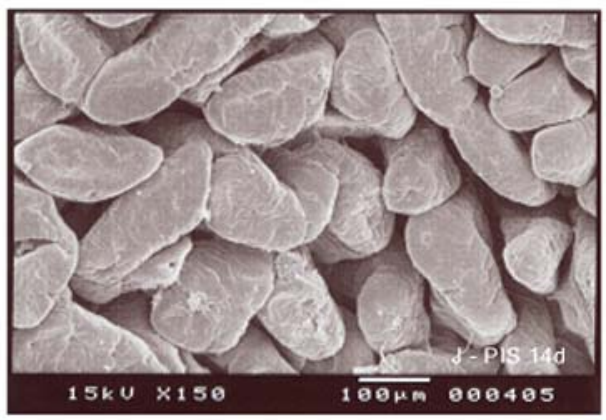

J-14 dias pós-desmame-PIS

$J-14-d a y-w e a n e d-I P S$

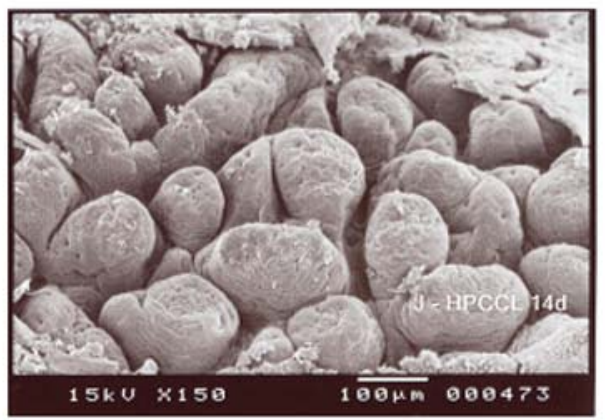

$\mathrm{J}-14$ dias pós-de smame-HPCCL $J-14-d$ ay-weaned - HPCCY

Figura 4 - Eletronmicrografias de varredura do jejuno $(\mathrm{J})$ de leitões ao desmame (controle) e aos 14 dias pós-desmame, em função das diferentes fontes protéicas (FS - farelo de soja, LPI - leite em pó integral, HPMIS - hidrolisado protéico de mucosa intestinal de suíno, PIS - proteína isolada de soja e HPCCL - hidrolisado protéico de conteúdo celular de levedura). $A=150 X$.

Figure 4 - Scan eletronmicrografies of jejuni (J) from weaning pigs (control) and 14-day-weaned pigs according to different protein sources (SM - soybean meal, WDM - whole dried milk. HPIMS - hydrolized protein of intestinal mucosa membrane of swine, IPS - isolated protein of soybean and HPCCY - hydrolized protein of cellular content of yeast). $I=150 X$.

R. Bras. Zootec., v.34, n.6, p.2355-2368, 2005 (supl.) 
Tabela 5 - Efeitos da idade e da dieta sobre a espessura $(\mathrm{mm})$ da mucosa $(\mathrm{M})$, submucosa (SB), muscular + serosa $(\mathrm{Mu}+\mathrm{Se})$ e total $(\mathrm{T})$ da parede intestinal de leitões

Table 5 - Effects of age and diets on mucosa (M), submucosa (S), muscular + serosa (Mu+Se) and total thickness (T) of intestinal wall of pigs

\begin{tabular}{|c|c|c|c|c|c|c|c|c|}
\hline \multirow{3}{*}{$\begin{array}{l}\text { Causa de variação } \\
\text { Source of variation }\end{array}$} & \multicolumn{8}{|c|}{$\begin{array}{l}\text { Túnica da parede intestinal } \\
\text { Intestinal wall layer }\end{array}$} \\
\hline & \multicolumn{4}{|c|}{$\begin{array}{l}\text { Duodeno } \\
\text { Duoden }\end{array}$} & \multicolumn{4}{|c|}{$\begin{array}{c}\text { Jejuno } \\
\text { Jejuni }\end{array}$} \\
\hline & M & SM & $\mathrm{Mu}+\mathrm{Se}$ & ET & M & SM & $\mathrm{Mu}+\mathrm{Se}$ & ET \\
\hline & \multicolumn{8}{|c|}{$\begin{array}{l}\text { Nível de significância pelo teste F } \\
\text { Significance level by F test }\end{array}$} \\
\hline \multicolumn{9}{|l|}{ Idade } \\
\hline Age & 0,01 & 0,01 & 0,01 & 0,01 & 0,01 & 0,01 & 0,01 & 0,01 \\
\hline Dieta & 0,50 & 0,87 & 0,82 & 0,71 & 0,80 & 0,81 & 0,66 & 0,87 \\
\hline \multicolumn{9}{|l|}{ Diet } \\
\hline Interação & 0,24 & 0,71 & 0,54 & 0,45 & 0,47 & 0,73 & 0,48 & 0,69 \\
\hline Interaction & & & & & & & & \\
\hline $\mathrm{CV}(\%)^{*}$ & 10,1 & 15,7 & 16,0 & 10,0 & 12,6 & 10,9 & 14,0 & 8,8 \\
\hline Dia & \multirow{2}{*}{\multicolumn{8}{|c|}{$\begin{array}{c}\text { Média }(\mathrm{mm})^{2} \\
\text { Mean }\end{array}$}} \\
\hline Day & & & & & & & & \\
\hline 0 & $747^{\mathrm{a}}$ & $1193^{b}$ & $328^{\mathrm{b}}$ & $2268^{b}$ & $552^{\mathrm{a}}$ & $1234^{\mathrm{b}}$ & $327^{\mathrm{b}}$ & $2113^{b}$ \\
\hline 7 & $691^{b}$ & $1273^{a b}$ & $374^{\mathrm{b}}$ & $2264^{b}$ & $473^{b}$ & $1198^{b}$ & $311^{\mathrm{b}}$ & $1982^{b}$ \\
\hline 14 & $616^{\mathrm{c}}$ & $1416^{\mathrm{a}}$ & $451^{\mathrm{a}}$ & $2557^{\mathrm{a}}$ & $546^{\mathrm{a}}$ & $1488^{a}$ & $429^{a}$ & $2463^{a}$ \\
\hline Dieta $^{1}$ & \multicolumn{8}{|c|}{ Média $(\mathrm{mm})^{2}$} \\
\hline Diet & \multicolumn{8}{|c|}{ Mean } \\
\hline $\mathrm{FS}(S M)$ & 659 & 1285 & 377 & 2322 & 520 & 1282 & 363 & 2165 \\
\hline LPI $(D W M)$ & 706 & 1348 & 395 & 2448 & 511 & 1318 & 348 & 2178 \\
\hline LPI+HPMIS (DWM+HPIMS) & 676 & 1291 & 398 & 2365 & 521 & 1331 & 370 & 2223 \\
\hline $\mathrm{LPI}+\mathrm{PIS}(D W M+I P S)$ & 697 & 1263 & 375 & 2336 & 544 & 1327 & 341 & 2213 \\
\hline LPI+HPCCL $(D W M+H P C C Y)$ & 685 & 1284 & 375 & 2344 & 520 & 1276 & 355 & 2151 \\
\hline
\end{tabular}

${ }^{1} \mathrm{FS}$ (farelo de soja), LPI (leite em pó integral); LPI+HPMIS (leite em pó integral + hidrolisado protéico de mucosa intestinal de suíno); LPI+PIS (leite em pó integral + proteína isolada de soja); LPI+HPCCL (leite em pó integral + hidrolisado protéico do conteúdo celular de levedura). 2 Médias com letras iguais na mesma coluna não diferem $(P>0,05)$ pelo teste Tukey. ${ }^{*} C V \%$ - coeficiente de variação.

1 SM (soybean meal), DWM (dried whole milk), DWM+HPIMS (dried whole milk + hydrolized protein of intestinal mucosa membrane of swine), DWM+IPS (dried whole milk + isolated protein of soybean), DWM +HPCCY (hydrolized protein of cellular content of yeast).

${ }^{2}$ Means followed by the same letters in a column do not differ $(P>0.05)$ by Tukey test. ${ }^{*} C V \%$ - coefficient of variation.

pós-desmame, a espessura da mucosa era ainda $17 \%$ inferior à verificada no dia zero, enquanto a submucosa e a muscular + serosa apresentavam incrementos de 18,6 e $37,5 \%$, respectivamente. Comportamento semelhante foi observado no jejuno. Desta forma, o aumento $(\mathrm{P}<0,05)$ na espessura total da parede do jejuno aos 14 dias pós-desmame ocorreu principalmente em razão dos incrementos nas camadas submucosa e muscular + serosa.

O significativo efeito da idade sobre a morfologia intestinal, em detrimento às dietas experimentais, está relacionado ao grande impacto que a presença de alimento no tubo digestório tem sobre a mucosa gastrointestinal (Kelly et al., 1991; Pluske et al., 1996), que é superior à própria composição da dieta
(McCracken et al., 1995 e 1999). Além disso, o trato digestório é o órgão de maior atividade metabólica do corpo e, em períodos de baixa ingestão de alimentos (como o subseqüente à desmama), pode sofrer redução de seu desenvolvimento, para redirecionamento parcial da energia para outros tecidos (Touchette \& Allee, 2000).

O peso absoluto do pâncreas aumentou $(\mathrm{P}<0,05)$ com a idade após o desmame (Tabela 6), indicando maior desenvolvimento e maturação da capacidade digestiva dos animais com as novas dietas (Owsley et al., 1986). Vente-Spreeuwenberg et al. (2003) também verificaram aumento do peso absoluto do pâncreas entre 3 e 7 dias pós-desmame. Além disso, a diferença conforme a idade é também esperada, pois o peso das

R. Bras. Zootec., v.34, n.6, p.2355-2368, 2005 (supl.) 
Tabela 6 - Efeitos da idade e da dieta sobre os pesos absoluto e relativo do pâncreas (g de pâncreas/ $\mathrm{kg}$ de carcaça) de leitões

Table 6 - Effects of age and diet on absolute and relative weights of pancreas ( $\mathrm{g}$ pancreas/kg carcass) of pigs

\begin{tabular}{lcc}
\hline $\begin{array}{l}\text { Causa de variação } \\
\text { Source of variation }\end{array}$ & $\begin{array}{c}\text { Peso absoluto do pâncreas } \\
\text { Absolute weight of pancreas }\end{array}$ & $\begin{array}{c}\text { Peso relativo do pâncreas } \\
\text { Relative weight of pancreas }\end{array}$ \\
\hline Idade (Age) & 0,01 & 0,01 \\
Dietas (Diets) & 0,04 & 0,02 \\
Interação (Interaction) & 0,19 & 0,05 \\
CV $(\%)^{*}$ & 26,7 & 21,1 \\
Dia & Média $(\mathrm{g})$ & Média $(\mathrm{g} / \mathrm{kg})$ \\
Day & Mean $(\mathrm{g})$ & Mean $(\mathrm{g} / \mathrm{kg})$ \\
0 & $8,42 \mathrm{c}(2)$ & 2,28 \\
7 & $12,45 \mathrm{~b}$ & 3,22 \\
14 & $15,09^{\mathrm{a}}$ & 3,31 \\
Dieta & Média $(\mathrm{g})$ & Média $(\mathrm{g} / \mathrm{kg})$ \\
Diet & Mean $(\mathrm{g})$ & Mean $(\mathrm{g} / \mathrm{kg})$ \\
FS $(S M)$ & $11,442 \mathrm{ab}$ & 2,81 \\
LPI $(D W M)$ & $11,233 \mathrm{ab}$ & 2,84 \\
LPI+HPMIS $(D W M+H P I M S)$ & $11,592 \mathrm{ab}$ & 2,87 \\
LPI+PIS $(D W M+I P S)$ & $14,733^{\mathrm{a}}$ & 3,49 \\
LPI+HPCCL $(D W M+H P C C Y)$ & $10,945 \mathrm{~b}$ & 2,66 \\
\hline
\end{tabular}

${ }^{1} \mathrm{FS}$ (farelo de soja), LPI (leite em pó integral); LPI+HPMIS (leite em pó integral + hidrolisado protéico de mucosa intestinal de suíno); LPI+PIS (leite em pó integral + proteína isolada de soja); LPI+HPCCL (leite em pó integral + hidrolisado protéico do conteúdo celular de levedura).

${ }^{2}$ Médias com letras iguais na mesma coluna não diferem entre si pelo teste Tukey $(P>0,05)$. ${ }^{*} \mathrm{CV} \%$ - coeficiente de variação.

1 SM (soybean meal), DWM (dried whole milk), DWM+HPIMS (dried whole milk + hydrolized protein of intestinal mucosa membrane of swine), DWM+IPS (dried whole milk + isolated protein of soybean), DWM+HPCCY (hydrolized protein of cellular content of yeast).

2 Means followed by the same letters in a column do not differ $(P>0.05)$ by Tukey test. ${ }^{*} \mathrm{CV} \%$ - coefficient of variation.

Tabela 7 - Desdobramento da interação idade $\times$ ração indicado na Tabela 6

Table 7 - Age $\times$ diet interaction as indicated in Table 6

\begin{tabular}{lcc}
\hline Ração $^{1}$ & \multicolumn{2}{c}{ Dia $^{2}$} \\
Diet & \multicolumn{2}{c}{ Day } \\
\cline { 2 - 3 } & $2,64 \mathrm{~b}$ & 14 \\
\hline FS $(S M)$ & $2,96 \mathrm{~b}$ & 3,52 \\
LPI $(D W M)$ & $3,26 \mathrm{ab}$ & 3,29 \\
LPI+HPMIS (DWM+HPIMS) & $4,60 \mathrm{Aa}$ & $3,00 \mathrm{~B}$ \\
LPI+PIS (DWM+IPS) & $2,63 \mathrm{~b}$ & 3,08 \\
LPI+HPCCL $(D W M+H P C C Y)$ & \\
\hline
\end{tabular}

${ }^{1}$ FS (farelo de soja), LPI (leite em pó integral); LPI+HPMIS (leite em pó integral + hidrolisado protéico de mucosa intestinal de suíno); LPI+PIS (leite em pó integral + proteína isolada de soja); LPI+HPCCL (leite em pó integral + hidrolisado protéico do conteúdo celular de levedura).

2 Médias com letras iguais na mesma coluna não diferem $(P>0,05)$ pelo teste Tukey. ${ }^{*} \mathrm{CV} \%$ - coeficiente de variação.

1 SM (soybean meal), DWM (dried whole milk), DWM+HPIMS (dried whole milk + hydrolized protein of intestinal mucosa membrane of swine), $D W M+I P S$ (dried whole milk + isolated protein of soybean), DWM+HPCCY (hydrolized protein of cellular content of yeast).

2 Means followed by the same letters in a column do not differ $(P>0.05)$ by Tukey test. ${ }^{*} \mathrm{CV} \%$ - coefficient of variation. vísceras acompanha o aumento do peso corporal dos animais até a idade adulta (Moran Jr., 1982), o que justifica a ausência de efeito $(\mathrm{P}>0,05)$ da idade sobre o peso relativo do pâncreas (Tabela 6).

A ração com leite em pó integral + proteína isolada de soja proporcionou maior $(\mathrm{P}<0,05)$ peso de pâncreas que aquela contendo leite em pó integral + hidrolisado protéico de conteúdo celular de levedura, que não diferiu $(\mathrm{P}>0,05)$ dos demais. Estes dados diferem dos obtidos por Silz (2000), que não verificou efeito da proteína isolada de soja em combinação com leite em pó sobre o peso do pâncreas.

Entretanto, o menor peso do pâncreas observado para a dieta contendo leite em pó integral + hidrolisado protéico de conteúdo celular de levedura sugere que esta dieta tenha menor capacidade de estimular o desenvolvimento do pâncreas e que necessite de menor produção de enzimas pancreáticas para a digestão protéica.

Não se observou efeito $(\mathrm{P}>0,05)$ das dietas sobre o desenvolvimento relativo do pâncreas (Tabela 6), 
mas houve interação $(\mathrm{P}<0,05)$ dieta $\mathrm{x}$ idade, cujo desdobramento (Tabela 7) comprovou que os animais alimentados com as dietas contendo leite em pó integral e proteína isolada de soja ou hidrolisado protéico de membrana intestinal suína apresentaram pesos relativos do pâncreas, aos 7 dias pós-desmame, superiores aos demais animais, porém, esses pesos não diferiram $(\mathrm{P}>0,05)$ aos 14 dias. Portanto, essas duas dietas foram mais eficientes em estimular o desenvolvimento do pâncreas logo após o desmame. Os leitões que receberam a ração contendo leite em pó integral e proteína isolada de soja apresentaram maior $(\mathrm{P}<0,05)$ peso relativo de pâncreas aos 7 que aos 14 dias pós-desmame.

\section{Conclusões}

As fontes protéicas avaliadas não foram capazes de minimizar os efeitos deletérios da mudança de alimentação à desmama sobre a morfologia intestinal dos leitões. Os efeitos do uso de proteína isolada de soja, hidrolizado protéico de mucosa intestinal de suínos e hidrolisado protéico de conteúdo celular de levedura sobre o desenvolvimento pancreático indicaram a potencialidade de sua adição em dietas para leitões à desmama. Entretanto, porém mais pesquisas devem ser realizadas, principalmente para avaliação do produto obtido de levedura.

\section{Literatura Citada}

ARGENZIO, R.A. Digestão absorção e metabolismo. In: SWENSON, M.J. (Ed.) Dukes: fisiologia dos animais domésticos. 11.ed. Rio de Janeiro: Guanabara Koogan, 1993. p.253-272.

BEHMER, O.A.; De TOLOSA, E.M.C.; NETO, A.G.F. Manual de técnicas para histologia normal e patológica. São Paulo: EDART, 1976. 241p.

BUDIÑO, F.E.L.; THOMAZ, M.C.; KRONKA, R.N. et al. Efeitos da adição de probiótico e/ou prebiótico na dieta de leitões desmamados sobre a estrutura do intestino delgado. In: REUNIÃO ANUAL DA SOCIEDADE BRASILEIRA DE ZOOTECNIA, 40., 2003, Santa Maria. Anais... Santa Maria: Sociedade Brasileira de Zootecnia, 2003 (CD-ROM).

CARLSON, M.S.; VEUM, T.L. A comparison between feeding peptide and plasma proteins on nursery pig growth performance and intestinal health. Missouri: University of Missouri, 2000. p.3. (Report)

CERA, K.R.; MAHAN, D.C.; CROSS, R.F. Effect of age, weaning and post-weaning diet on small intestinal growth and jejunal morphology in young swine. Journal of Animal Science, v.66, n.2, p.574-584, 1988.

CERF-BENSUSSSAN, N.; GUY-GRAND, D. Mucosal immunology I: Principles. Intestinal intraepithelial lymphocytes. Gastroenteroly Clinics of North America, v.20, n.3, p.549-576, 1991.
DUNSFORD, B.R.; KNABE, D.A.; HAENSLY, W.E. Effect of dietary soybean meal on the microscopic anatomy of the small intestine in the early weaned pig. Journal of Animal Science, v.67, n.7, p.1855-1863, 1989.

EFFIRD, R.C.; ARMSTRONG, W.D.; HERMAN D.L. The development of digestive capacity in young pigs: effects of age and weaning system. Journal of Animal Science, v.55, n.6, p.1380-1387, 1982.

HAMPSON, D.J. Alterations in piglet small intestine structure at weaning. Research Veterinarian Science, v.40, p.32-40, 1986a.

HAMPSON, D.J. Attempts to modifiy changes in the piglet small intestine structure after weaning. Research Veterinarian Science, v.40, p.313-317, 1986 b.

HANNAS, M.I. Plasma suíno e ovo inteiro desidratados em substituição à proteína bruta do leite em pó nas rações de leitões. Jaboticabal: Universidade Estadual Paulista, 2003. 149p. Tese (Doutorado em Produção Animal) - Universidade Estadual Paulista, 2003.

JIANG R.; CANG, X.; STOLL, B. et al. Dietary plasma protein reduces small intestinal growth and lamina propria cell density in early-weaned pigs. Journal of Nutrition, v.130, n.1, p.21-26, 2000.

KELLY, D.; SMYTH, J.A.; McCRAKEN, K.J. Digestive development of the early weaned pig. British Journal of Nutrition, v.65, n.2, p.169-180, 1991.

LI, D.F.; NELSSEN, J.L.; REDDY, P.G. et al. Transient hypersensitivity to soybean meal in the early weaned pig. Journal of Animal Science, v.68, n.6, p.1790-1799, 1990.

LI, D.F.; NELSSEN, J.L.; REDDY, P.G. et al. Interrelationship between hypersensitivity to soybean proteins and growth performance in early weaned pigs. Journal of Animal Science, v.69, n. 8, p.4062-4069, 1991.

LUDKE, J.V.; BERTOL, T.M.; SCHEUERMANN, G.N. Manejo da alimentação. In: SOBESTIANSKY, J.; WENTZ, I.; SILVEIRA, P.R.S. (Eds.) Suinocultura intensiva. Produção, manejo e saúde do rebanho. Concórdia: EMBRAPA-CNPSA, 1998. p.65-90.

McCRACKEN B.A.; GASKINS, H.R.; RUWENKAISER, P.J. et al. Diet-dependent and diet-independent metabolic responses underlie growth homeostasis of pigs at weaning. Journal of Nutrition, v.125, p.2838-2845, 1995.

McCRACKEN, B.A.; SPURLOCK, M.E.; ROOS, M.A. Weaning anorexia may contribute to local inflammation in the piglet small intestine. Journal of Nutrition, v.129, p.613-619, 1999.

MILLER, B.G.; NEWBY, T.J.; STOKES, C.R. et al. The importance of dietary antigen in the cause of postweaning diarrhea in pigs. American Journal of Veterinary Research, v.45, n.9, p.1730-1733, 1984.

MORAN JR., E.T. Comparative nutritional of fowl and swine: the gastrointestinal systems. Ontario: University Guelph, 1982. 253p.

NATIONAL RESEARCH COUNCIL. Nutrient requirements of swine. 10.ed. Washington, D.C.: National Academic Science, 1998. 189p.

OWSLEY, D.F.; ORR, JR.; TRIBBLE, L.F. Effects of age and diet on the development of the pancreas and the synthesis and secretion of pancreatic enzymes in the young pig. Journal of Animal Science, v.63, n.2, p.497-504, 1986.

PIERZYNOWSKY, S.G. et al. Induction of exocrine pancreas maturation at weaning in young developing pigs. Journal of Pediatric Gastroenterology and Nutrition, v. 16, p.287-293, 1993. 
PLUSKE, J.R.; WILLIAMS, I.H.; AHERNE, F.X. Maintenance of villous height and crypt depth in piglets by providing continuous nutrition after weaning. Animal Science, v.62, p.131-144, 1996.

PLUSKE, J.R.; HAMPSON, D.J.; WILLIAMS, I.H. Factors influencing the structure and function of the small intestine in the weaned pig: a review. Livestock Production Sciences, Amsterdam, v.51, n.3, p.215-236, 1997.

RIBEIRO, P.R. Efeitos da adição de betaína na ração de suínos, sobre a incidência de diarréia, desempenho e características de carcaça. Jaboticabal: Universidade Estadual Paulista, 2000. 66p. Tese (Doutorado em Produção Animal) - Universidade Estadual Paulista, 2000.

SANTOS, W.G.; FILGUEIRAS, E.P.; SILVA, H.O. et al. Efeito da manose como prebiótico sobre a morfologia intestinal (relação vilosidade/cripta) de leitões na fase de creche. In: REUNIÃO ANUAL DA SOCIEDADE BRASILEIRA DE ZOOTECNIA, 39., 2002, Recife: Anais... Recife: Sociedade Brasileira de Zootecnia, 2002. CD-ROM.

STATISTICAL ANALYSES SYSTEM - SAS. SAS/STAT user's guide. Cary: $1985.956 \mathrm{p}$.

SILZ, L.Z. Fontes de proteína para leitões em fase inicial de crescimento. Jaboticabal: Universidade Estadual Paulista, 2000. 65p. Tese (Doutorado em Produção Animal) - Universidade Estadual Paulista, 2000.
TOUCHETTE, K.J.; ALLEE, G.L. Efectos de la nutritión sobre la salud intestinal y el crescimento de lechones. In: Curso de Especialización FEDNA - Avances en nutrición y alimentación animal, 15., 2000, Madrid. Anais... Madrid: FEDNA, 2000, 14p. Disponível em <http://www.etsia.upm.es/fedna/ mainpageok.html $>$. Acesso em 10 fev.2002.

TUCCI, F.M. Efeitos da adição de agentes tróficos na dieta de leitões desmamados sobre a renovação celular da mucosa intestinal, enzimas digestivas e desempenho. Jaboticabal: Universidade Estadual Paulista, 2003. 84p. Tese (Doutorado em Produção Animal) - Universidade Estadual Paulista, 2003.

VENTE-SPREEUWENBERG, M.A.M.; VERDONK, J.M.A.J.; BEYNEN, A.C. et al. Interrelationships between gut morphology and faeces consistency in newly weaned piglets. Animal Science, v.77, n.3, p.85-94, 2003. 